\title{
LINSEED OIL
}

I. P. Nazarova, A. I. Glushenkova,

UDC $542.941+665.35$ and A. L. Markman

We have investigated the selectivity of the hydrogenation of linseed oil, which is a mixture of triglycerides of fatty acids of different degrees of unsaturation - linolenic, linoleic, and oleic - and saturated fatty acids. Depending on the conditions of hydrogenating oils and fats, the process may go according to the following scheme, given in the literature [1]:

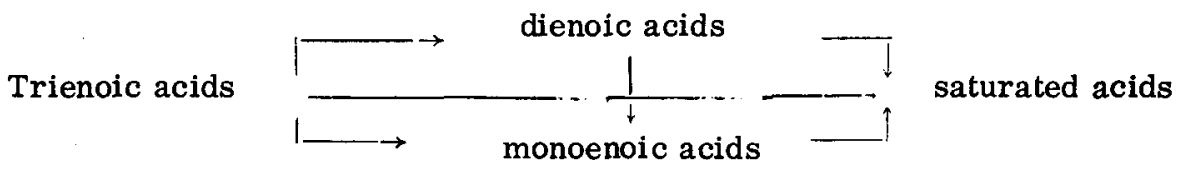

Opinions on the question of the consecutive saturation of triglyceride oils containing linolenic acid are contradictory [1-4]. The linseed oil that we used for hydrogenation had the following fatty-acid composition according to GLC (\%): $\mathrm{C}_{16: 0}-8.5 ; \mathrm{C}_{16: 1}-0.4 ; \mathrm{C}_{18: 0}-2.6 ; \mathrm{C}_{18: 1}-21.2 ; \mathrm{C}_{18: 2}-21.0 ; \mathrm{C}_{18: 3}-46.3$. To free it from mucilages, the oil was passed in the form of a miscella through a column of alumina.

We studied the direction of the hydrogenation process as a function of the conditions by analyzing the fatty-acid compositions of the initial oil and of the intermediate and final hydrogenation products. The fattyacid composition of linseed oil changed when it was hydrogenated in ethanol (at $60^{\circ} \mathrm{C}$ with $0.05 \mathrm{Pd} / \mathrm{Al}$ ). The saturation of the oil up to the absorption of almost half of the amount of hydrogen calculated theoretically was accompanied by a sharp decrease in the amount of linolenic acid and a rise in the amount of oleic acid, while the amounts of linoleic and stearic acids remained constant. Appreciable saturation of the linoleic acid was begun only with a fall in the amount of linolenic to $50 \%$. Simultaneously with the hydrogenation of linoleic acid, a marked increase in the amounts of oleic and stearic acids was obse rved.

When the oil was hydrogenated with $1 \%$ of a previously reduced $\left(220-230^{\circ} \mathrm{C}\right)$ palladium catalyst at $120^{\circ} \mathrm{C}$, again a decrease in the amount of linolenic acid with a simultaneous increase in the amount of oleic acid and constancy of the amounts of linoleic and stearic acids took place. Intensive saturation of the linoleic acid radicals was observed when the concentrations of the latter and the linolenic acid were equal.

Raising the temperature of hydrogenation to $210^{\circ} \mathrm{C}$ considerably intensified the process, but its direction remained the same as before. We have observed a similar pattern in the hydrogenation of linseed oil with $1 \%$ of previously reduced platinum and nickel-copper $(1: 1)$ catalysts at $120^{\circ} \mathrm{C}$.

Thus, regardless of the conditions of the process and of the catalysts, the hydrogenation of linseed oil was accompanied by the preferential saturation of the linolenic acid to the monoenoic acid. Linoleic acid begins to be hydrogenated only after a considerable fall in the amount of linolenic.

\section{LITERATURE CITED}

1. L. S. Golodova, Author's Abstract of Doctoral Dissertation, Alma-Ata (1973), p. 4.

2. L. S. Golodova, in: Liquid-Phase Catalytic Reactions [in Russian], Alma-Ata (1967), p. 911.

3. A. E. Bailey, J。 Am. Oil Chemists' Soc., 26, 644 (1949).

4. A. E. Johnston, D. MacMillan, H. J. Dutton, and J. C. Cowan, J. Am. Oil Chemists' Soc., 39, 273 (1962).

Institute of the Chemistry of Plant Substances, Academy of Sciences of the Uzbek SSR, Tashkent. Translated from Khimiya Prirodnykh Soedinenii, No. 1, pp. 89-90, January-February, 1976. Original article submitted July $1,1975$.

This material is protected by copyright registered in the name of Plenum Publishing Corporation, 227 West 17 th Street, New York, N.Y. 10011. No part of this publication may be reproduced, stored in a retrieval system, or transmitted, in any form or by any means, electronic, mechanical, photocopying, microfiming, recording or otherwise, without written permission of the publisher. A copy of this article is available from the publisher for $\mathbf{3 7 . 5 0 .}$ 